\title{
UPAYA PENINGKATAN FITOREMEDIASI \\ TANAHTERCEMAR MERKURI \\ DI KOKAP KULONPROGO YOGYAKARTA MENGGUNAKAN AKASIA (Acacia sieberiana DC) DENGAN PEMANGKASAN AKAR DAN INOKULASI MIKORIZA
}

\author{
Akhsin Zulkoni* \\ *Dosen Negeri Kopertis V, DPK ITY STTL Yogyakarta
}

\begin{abstract}
INTISARI
Penelitian ini bertujuan untuk mengkaji upaya peningkatan fitoremediasi tanah tercemar merkuri di Kokap Kulon Progo Daerah Istimewa Yogyakarta menggunakan Akasia dengan pemangkasan akar (under ground root pruning/URP) dan inokulasi mikoriza.Penelitian ini dilaksanakan menggunakan rancangan acak kelompok lengkap dengan tiga ulangan.Faktor pertama adalah URP, yaitu dengan dan tanpa URP (pemangkasan akar). Faktor kedua ialah takaran Jamur Mikoriza Arbuskula (JMA), meliputi 0 ; 50; 100, dan 150 g/pot. Hasil penelitian telah membuktikan bahwa pemangkasan akar serta inokulasi JMA ke dalam tanah sisa olahan penambangan emas telah berhasil memacu proses fitoremediasi melalui perluasan rizosfer. Serapan merkuri oleh tanaman Akasia (Acacia sieberiana DC) yang menjalani pemangkasan akar serta inokulasi JMA sebanyak $100 \mathrm{~g}$ paling tinggi dibanding perlakuan lain maupun kontrol. Pada perlakuan ini, efisiensi penurunan merkuri di dalam tanah oleh tanaman Akasia sebesar 71,83 \%, sedangka kontrol hanya mencapai 35,33\%.

Kata kunci: fitoremediasi, jati, merkuri, pemangkasan akar, pencemaran , tanah.
\end{abstract}

\section{ENHANCEMENT EFFORT PHYTOREMEDIATION OF MERCURY CONTAMINATED SOIL IN KOKAP KULONPROGO YOGYAKARTA USING Acacia sieberiana DC WITH UNDERGROUND ROOT PRUNNING AND MYCORRHIZAL INOCULATION}

\begin{abstract}
This study aims to analyze the phytoremediation improvement of mercurycontaminated soil in Kokap Kulon Progo of Yogyakarta Special Region using Acacia sieberiana DC with underground root pruning (URP) and mycorrhizal inoculation. The study was conducted using a complete randomized block design with three replications.The first factor is the URP, that are with and without URP (underground root pruning). The second factor is the dose of JMA, are 0; 50; 100, and $150 \mathrm{~g} / \mathrm{pot}$. Results of studies have proven that the root pruning and inoculation of JMA into the residual gold mining soil has successfully accelerated the process of phytoremediation through the expansion of the rhizosphere. Mercury uptake by Acacia sieberiana DC, Linn $F$ that is with root pruning and $100 \mathrm{~g}$ JMA inoculation are highest other treatment and control. In this treatment, the removal efficiency of mercury in the soil by plants amounted to $71,83 \%$ identity, meanwhile control only reached $35,33 \%$.
\end{abstract}

Keywords: phytoremediation, Acacia sieberiana DC., mercury, under ground root pruning, contamination, soil 


\section{A. PENDAHULUAN}

Fitoremediasi adalah penggunaan tumbuhan untukmenghilangkan,memindahkan, men-stabilkan, atau menghancurkan bahan pencemar baik senyawa organik maupun anorganik (Purakayastha dkk., 2010). Keuntungan fitoremediasi adalah prosesnya dapat dilakukan secara insitu dan eksitu, mudah diterapkan dan tidak memerlukan biaya yang tinggi, teknologi yang ramah lingkungan dan bersifat estetik bagi lingkungan, serta dapat mereduksi kontaminan dalam jumlah yang besar. Sedangkan kerugian fitoremediasi ini adalah prosesnya memerlukan waktu lama, bergantung kepada keadaan iklim, dapat menyebabkan terjadinya akumulasi logam berat pada jaringan dan biomasa tumbuhan, dan dapat mempengaruhi keseimbangan rantai makanan pada ekosistem (Caroline, 2015).

Pemilihan tanaman yang dapat digunakan sebagai fitoremediator dipilih tanaman yang mempunyai sifat: cepat tumbuh, mampu mengkonsumsi air dalam jumlah yang banyak pada waktu yang singkat, mampu meremediasi lebih dari satu polutan, dan toleransi yang tinggi terhadap polutan (Morel dkk., 2006).

Indonesia memiliki modal penting berupa keragaman hayati sehingga sangat memungkinkan untuk mendapatkan sumber tanaman hiperakumulator. Hasil penelitian melaporkan bahwa tanaman eceng gondok dapat menyerap hingga 180 ppm $\mathrm{Pb}$ dan telah digunakan diantaranya untuk membersihkan silver salt dari air limbah prossesing foto (Pane dan Hasanudin, 2001). Tanaman akar wangi yang dapat tumbuh pada media dengan kadar $\mathrm{Pb}$ hingga 300 ppm bisa digunakan untuk rehabilitasi lahan tercemar logam berat (Emmyzar dan Hermanto, 2004). Tanaman melati air (Echinodorus palaefolius) mampu menyerap logam timbal $(\mathrm{Pb})$ dalam reaktor limbah sebesar $55,97 \%$ sedangkan dalam reaktor kontrol sebesar 0\% (Caroline, 2015).

Beberapa studi telah menunjukkan bahwa tanaman dapat mengakumulasi $\mathrm{Cd}$ dalam tubuh Eichornia crassipes, Brassica napus, Avicenna marina, Lycopersicon esculentum, Wolffia globosa, Phytolacca Americana, Solanum nigrum, Typha domingensis, Sedum plumbizincicola, Thlaspi caerulescens, Helianthus annuus, Lolium perenne, Tagetes erecta, Charaaustralis, Jatropha curcas, Sedum alfredii, Atriplex halimus, Phragmites cummunis, Nitella opaca, Phragmites australis, Typhaangus tifolia, Cyperus esculentus, Chara aculeolata, Ricinus communis, Hibiscus cannabinus, Zea mays, Arabidopsis halleri, Arundo donax, dan Vetiveria zizanioides (Nur, 2013). 
Mekanisme kerja fitoremediasi mencakup proses fitoekstraksi, rhizofiltrasi, fitodegradasi, fitostabilisasi dan fitovolatilisasi. Fitoekstraksi adalah penyerapan logam berat oleh akar tanaman dan mengakumulasi logam berat tersebut ke bagian-bagian tanaman seperti akar, batang dan daun.Rhizofiltrasi adalah pemanfaatan kemampuan akar tanaman untuk menyerap, mengendapkan, mengakumulasi logam berat dari aliran limbah. Fitodegradasi adalah metabolisme logam berat di dalam jaringan tanaman oleh enzim seperti dehalogenase dan oksigenase. Fitostabilisasi adalah kemampuan tanaman dalam mengekkresikan (mengeluarkan) suatu senyawa kimia tertentu untuk mengimobilisasi logam berat di daerah rizosfer (perakaran). Fitovolatilisasi terjadi ketika tanaman menyerap logam berat dan melepaskannya ke udara lewat daun dan ada kalanya logam berat mengalami degradasi terlebih dahulu sebelum dilepas lewat daun (Ghosh dan Singh, 2005).

Acacia merupakan jenis yang mulai banyak direkomendasikan untuk digunakan pada program GERHAN karena pada umumnya tumbuhan ini cepat tumbuh pada berbagai jenis tanah, mempunyai adaptasi yang luas dan tahan terhadap kondisi yang kurang menguntungkan (tidak memerlukan syarat tumbuh yang tinggi) (Djam'an dkk., 2006). Akasia mempunyai nama ilmiah Acacia sieberiana DC, termasuk famili Mimosaceae. Daun akasia majemuk, berhadapan, menyirip, lonjong, tepi rata, ujung dan pangkal tumpul, pertulangan daun menyirip. Daun berwarna hijau. Akasia mempunyai sistem perakaran tunggang, berwarna putih kotor.

Merkuri ( $\mathrm{Hg})$ merupakan logam dengan nomor atom 80, berbentuk cair pada suhu kamar, berwarna putih-keperakan, dan mudah menguap. Berat jenis merkuri lebih dari $59 \mathrm{~g} / \mathrm{cm}^{3}$, dan berat molekul sebesar 200,59. Sifat penting merkuri lainnya adalah kemampuannya untuk melarutkan logam lain dan membentuk logam paduan (alloy) yang dikenal sebagai amalgam.Kemampuan tersebut yang diambil dari merkuri untuk memisahkan emas dari ikatan logam yang lain. Sebagian besar logam bersifat immobile (termasuk merkuri), sehingga lebih banyak yang terakumulasi pada bagian akar (Nuryani dan Sutanto, 2002).

Perakaran merupakan landasan yang sangat penting pada pertumbuhan dan perkembangan tanaman.Pemotongan akar cenderung memperlambat pertumbuhan pucuk dan merangsang perkembangan sistem akar yang berserabut lebih hebat, sehingga rizosfer diperluas sampai mencapai 12 kali lipat (Marsono dan Soeseno, 1992). Pemotongan akar dapat perangsang percabangan akar (Kartika, 1997). 
Mikoriza adalah bentuk asosiasi antara jamur dan sistem perakaran tanaman tingkat tinggi (Marschner, 1991), serta tanah (Sieverding, 1991). Pada simbiosis ini,Jamur Mikoriza Arbuskula menghubungkan tanaman dengan tanah, dan mengangkut hara mineral dari tanah ke tanaman serta senyawa karbon dari tanaman ke dalam tanah. Sehubungan hal tersebut, maka JMA merupakan agensia nutrisi tanaman dan nutrisi tanah (Kabirun, 2004). JMA terkonsentrasi pada horizon tanah bagian atas yang banyak mengandung pupuk organik dan akar (Sieverding, 1991). JMA adalah jasad aerobik, oleh karenanya kondisi aerasi dan kadar lengas tanah berperan dalam distribusi dan efektifitasnya.Sieverding (1991) melukiskan bahwa miselium eksternal JMA bisa tumuh luas di dalam tanah (menempuh jarak $8 \mathrm{~cm}$ atau lebih dari akar). Bila rambut akar mampu menjangkau 1-2 $\mathrm{cm}^{2}$ volume tanah, maka miselium eksternal ini meningkatkan volume tanah yang terjangkau secara cepat hingga 5 -200 kali dengan asumsi radial hifa jamur di sekitar akar; atau $200 \mathrm{~cm}^{2}$ per $\mathrm{cm}$ akar yang terinfeksi jamur. Keadaan ini menyebabkan tanaman yang bermikoriza mengalami kontak dengan tanah lebih lama, sehingga unsur hara di dalam tanah tekuras, dan pupuk yang ditambahkan dapat diserap lebih efisien.
Mengingat merkuri sangat berpotensi mencemari lingkungan di daerah Kokap kabupaten Kulonprogo, maka patut mendapat perhatian serius, agar tidak berdampak negatif kepada penduduk sekitar. Pada paper ini dipilih penggunaan satu metoda remediasi merkuri yang mudah, berbahan baku lokal, yaitu fitoremediasi menggunakan tanaman Akasia. Pengelolaan medium pertumbuhan dan perlakuan fisiologis tumbuhan adalah peluang yang dapat ditangani sebagai upaya peningkatan fitoremediasi. Proses fisiologis tanaman ditingkatkan dengan pemotongan akar atau underground root pruning (URP) yang akan menghambat pembentukan akar pucuk serta merangsang pembentukan serabut dan bulu-bulu akar. Inokulasi JMA akan memperbaiki sifat fisika, kimia dan biologi tanah serta mamacu pertumbuhan tanaman.

\section{B. METODE PENELITIAN}

Penelitian ini dilaksanakan pada bulan Maret sampai dengan Nopember 2016 di dusun Noyokerten Sendangtirto, Berbah, , Sleman, Daerah Istimewa Yogyakarta. Percobaan dilakukan pada skala laboratorium, menggunakan rancangan acak kelompok lengkap dengan tiga ulangan.Faktor pertama adalah URP, yaitu dengan dan tanpa URP (pemangkasan akar). Faktor kedua 
ialah takaran JMA, meliputu 0; 50; 100, dan $150 \mathrm{~g} /$ pot.

Tanah diambil dari sisa pengolahan penambangan emas di Kokap, kabupaten Kulonprogo kemudian dibawa ke lokasi penelitian. Tanaman Akasia yang ditanam berumur tiga bulan.Akar dibersihkan dari tanah, lalu dilakukan pemangkasan dua per tiga dari leher akar.JMA dimasukkan ke dalam lubang tanam sesuai dengan takaran yang telah ditentukan.Penelitian berlangsung selama delapan bulan.Setiap dua hari dilakukan penyiraman air berdasar pada kapasitas lapangan. Parameter yang dianalisis meliputi pertumbuhan tanaman, kadar $\mathrm{Hg}$ (metode AAS) di dalam akar dan tanah, serapan $\mathrm{Hg}$ dan efisiensi penurunan $\mathrm{Hg}$ dalam tanah. Data hasil penelitian dianalisis menggunakan Anova $\alpha 1 \%$ dan $\alpha$ $5 \%$. Bila ada beda nyata, dilanjutkan uji BNT a 5\% (Gomez and Gomez, 1994).
Tanah yang diteliti adalah sisa olahan penambangan emas yang dikerjakan secara tradisional oleh masyarakat dusun Sangon .Kecamatan Kokap Kabupaten Kulonprogo Yogyakarta. Pada analisis awal, tanah tersebut mengandung merkuri sebesar 18 ppm. Nilai ini telah melebihi batas yang ditetapkan oleh Peraturan Menteri Republik Indonesia Nomor 82 (Anonim, 2001), yaitu kurang dari 0,01 ppm. Surat Keputusan Menteri Negara Lingkungan Hidup Nomor 202 tahun 2004 menjelaskan bahwa kadar merkuri dalam sedimen tidak boleh melebihi 0,005 ppm (Anonim, 2004).

\section{Pertumbuhan Akasia}

Pemangkasan akar dan inokulasi mikoriza ke dalam tanah terbukti bisa memacu pertumbuhan Akasia selama delapan bulan. Tabel 1 menyajikan data tinggi dan berat kering tanaman Akasia di akhir masa penanaman.

Tabel 1. Tinggi dan berat kering tanaman Akasia di akhir masa penanaman

\begin{tabular}{ccccccc}
\hline \multirow{2}{*}{$\begin{array}{c}\text { Takara } \\
\text { n JMA } \\
(\mathrm{g})\end{array}$} & \multicolumn{2}{c}{$\begin{array}{c}\text { Tinggi tanaman } \\
(\mathrm{cm})\end{array}$} & $\begin{array}{c}\text { Berat kering akar } \\
(\mathrm{g})\end{array}$ & \multicolumn{2}{c}{$\begin{array}{c}\text { Berat kering }(\mathrm{g}) \\
\text { trubus }\end{array}$} \\
\cline { 2 - 7 } & $\begin{array}{c}\text { UdkP } \\
\text { URngan }\end{array}$ & $\begin{array}{c}\text { Tdk. } \\
\text { URP }\end{array}$ & $\begin{array}{c}\text { Dengan } \\
\text { URP }\end{array}$ & $\begin{array}{c}\text { Tdk. } \\
\text { URP }\end{array}$ & $\begin{array}{c}\text { Dengan } \\
\text { URP }\end{array}$ \\
\hline 0 & $93,7 \mathrm{a}$ & $110 \mathrm{c}$ & $8,2 \mathrm{a}$ & $14,2 \mathrm{c}$ & $37,8 \mathrm{~b}$ & $38,1 \mathrm{~b}$ \\
\hline 50 & $102 \mathrm{~b}$ & $115 \mathrm{~d}$ & $11,4 \mathrm{~b}$ & $35,7 \mathrm{~d}$ & $33,3 \mathrm{a}$ & $41,0 \mathrm{c}$ \\
\hline 100 & $122,3 \mathrm{f}$ & $124,7 \mathrm{~g}$ & $13,7 \mathrm{c}$ & $37,1 \mathrm{e}$ & $47,3 \mathrm{~d}$ & $51,6 \mathrm{e}$ \\
\hline \multirow{2}{*}{150} & $\begin{array}{c}116,7 \\
\mathrm{e}\end{array}$ & $124 \mathrm{~g}$ & $15,5 \mathrm{c}$ & $36,2 \mathrm{e}$ & $42,9 \mathrm{c}$ & $48 \mathrm{~d}$ \\
\hline
\end{tabular}

Keterangan: huruf kecil yang sama di belakang angka pada tiap parameter, menunjukkan tidak ada beda antara satu dengan yang lain berdasar Uji BNT $\alpha$ $5 \%$. 
Pemangkasan akar telah memacu pertumbuhan tanaman melalui perluasan rizosfer. Pada perlakuan ini pertumbuhan akar pucuk dihambat, namun pertumbuhan akar lateral telah dipacu, sehingga penyerapan air dan unsur-unsur hara oleh akar tanaman. Pemenuhan unsur -unsur hara dan air mendorong proses metabolism tanaman, sehingga pertumbuhan tanamanpun menjadi lebih giat.Inokulasi mikoriza ke dalam medium pertumbuhan tanaman Akasia menambah perluasan daerah penyerapan akar. Berdasar analisis keragaman, ternyata takaran100 g per pot menjadi perlakuan yang terbaik bagi pertumbuhan Akasia. Pada perlakauan ini, tinggi tanaman pada akhir percobaan mencapai tinggi $124,7 \mathrm{~cm}$. Terdapat selisih 31 $\mathrm{cm}$ dari kontrol. Hal yang sama juga terjadi pada parameter berat kering baik akar maupun trubus. Berat kering akar sebesar 37,1 g dan berat kering trubus 51,6 g. Kondisi demikian sangat berbeda dengan kontrol.

\section{Kadar dan Serapan Hg oleh akar \\ Pada penelitian ini, merkuri} hanya ditemukan di dalam akar, sedangkan di dalam trubus tidak terdeteksi.Hal ini sesuai dengan pernyataan Nuryani dan Sutanto (2002) bahwa sebagian besar logam bersifat immobile (termasuk merkuri), sehingga lebih banyak yang terakumulasi pada bagian akar.Penyebab lainnya adalah kemungkinan waktu penanaman yang berlangsung selama delapan bulan.Berdasar kenyataan tersebut, kiranya perlu dilakukan penelitian yang serupa dengan waktu yang lebih lama untuk mengetahui berapa lama merkuri ditranslokasikan ke dalam jaringan trubus tanaman Akasia.Kadar Hg yang ada di dalam akar merupakan parameter kemampuan tanaman uji melakukan fitoremediasi terhadap tanah sisa olahan penambangan emas yang mengandung

merkuri.

Tabel 2. Rerata kadar Hg (ppb) dan serapan $\mathrm{Hg}(\mu \mathrm{g})$ oleh Akasia pada berbagai perlakuan

\begin{tabular}{|c|c|c|c|c|}
\hline \multirow{2}{*}{$\begin{array}{c}\text { Takaran JMA } \\
(\mathrm{g} / \mathrm{pot})\end{array}$} & \multicolumn{2}{|c|}{ Kadar Hg dalam akar $(\mathrm{ppb})$} & \multicolumn{2}{c|}{ Serapan Hg oleh akar $(\mu \mathrm{g})$} \\
\cline { 2 - 5 } & Tanpa URP & URP & Tanpa URP & URP \\
\hline 0 & $1,03 \mathrm{a}$ & $5,47 \mathrm{c}$ & $0,021 \mathrm{a}$ & $0,109 \mathrm{~b}$ \\
\hline 50 & $1,48 \mathrm{ab}$ & $5,83 \mathrm{c}$ & $0,030 \mathrm{a}$ & $0,117 \mathrm{~b}$ \\
\hline 100 & $2,04 \mathrm{~b}$ & $6,22 \mathrm{~d}$ & $0,041 \mathrm{a}$ & $0,124 \mathrm{c}$ \\
\hline 150 & $1,99 \mathrm{a}$ & $5,46 \mathrm{c}$ & $0,050 \mathrm{a}$ & $0,137 \mathrm{c}$ \\
\hline
\end{tabular}

Keterangan: huruf kecil yang sama di belakang angka pada tiap parameter menunjukkan tidak ada beda antara satu dengan yang lain berdasar Uji BNT $\alpha$ $5 \%$.

Sumber: Data primer, 2016 
Tabel 2 mencerminkan bahwa penyerapan merkuri oleh tanaman Akasia terbanyak terjadi pada tanaman yang menjalani pemangkasan akar serta diikuti dengan inokulasi JMA sebanyak 100 g/pot. Pada perlakuan ini kadar merkuri yang terkandung di dalam akar sebanyak 6,22 ppb dengan serapan seberat $0,124 \mu \mathrm{g}$. Bila dibandingkan dengan kontrol terdapat selisih kadar merkuri sejumlah 5,19 ppb dan beda serapan seberat $0,103 \mu \mathrm{g}$.

Penyerapan adalah suatu proses fisiologi yang menentukan keberhasilan fitoremediasi merkuri. Bagian tanaman yang berperan dalam proses ini yaitu akar. Tanaman yang mengalami pemangkasan akar bisa terjadi perangsangan perkembangan akar lateral atau percabangan akar (Kartika, 1997). Rambut-rambut akar merupakan bagian akar yang melakukan penyerapan secara aktif terhadap air beserta unsur hara, termasuk merkuri.

Disamping pemangkasan akar, inokulasi JMA ke dalam tanah sisa olahan penambangan emas juga memperluas daerah penyerapan air dan unsur hara, sehingga pertumbuhan tanaman menjadi lebih terpacu. Sieverding (1991) melukiskan bahwa miselium eksternal JMA bisa tumuh luas di dalam tanah (menempuh jarak $8 \mathrm{~cm}$ atau lebih dari akar). Bila rambut akar mampu menjangkau 1-2 $\mathrm{cm}^{2}$ volume tanah, maka miselium eksternal ini meningkatkan volume tanah yang terjangkau secara cepat hingga 5 -200 kali dengan asumsi radial hifa jamur di sekitar akar; atau $200 \mathrm{~cm}^{2}$ per $\mathrm{cm}$ akar yang terinfeksi jamur.

Berdasar keberadaan merkuri yang terakumulasi di akar, maka proses yang berlangsung pada fitoremediasi ini adalah fitoakumulasi atau fitoekstraksi yaitu proses tumbuhan menarik zat kontaminan dari media sehingga berakumulasi di sekitar akar tumbuhan. Akar tanaman menyerap limbah logam dari tanah dan mentranslokasinya ke bagian tanaman yang berada di atas tanah. Rizofilttrasi merupakan proses tumbuhan menarik zat kontaminan dari media sehingga berakumulasi di sekitar akar tumbuhan. Fitostabilisasi merupakan penempelan zat-zat kontaminan tertentu pada akar yang tidak mungkin terserap ke dalam batang tumbuhan. Zat-zat tersebut menempel erat (stabil) pada akar sehingga tidak akan terbawa oleh aliran air dalam media (Ghosh dan Singh, 2005).

3.

\section{fisiensi penurunan kadar merkuri di alam tanah}

Merkuri yang terkandung di dalam tanah akan mengalami perpindahan tempat, yaitu dari dalam 
tanah masuk ke dalam jaringan tumbuhan lewat penyerapan oleh bulu-bulu akar. Kadar Hg di dalam tanah setelah proses fitoremediasi disajikan dalam Gambar 2.

Tanah sisa olahan penambangan emas yang ditumbuhi tanaman Akasia selama delapan bulan mengalami penyerapan $\mathrm{Hg}$ oleh akar secara terus menerus. $\mathrm{Hg}$ akan berpindah tempat dari dalam tanah masuk ke dalam jaringan tanaman, sehingga $\mathrm{Hg}$ dalam tanah menjadi berkurang.Berdasar uji keragaman, ternyata tanaman yang mengalami pemangkasan akar maupun inokulasi JMA mampu menurunkan merkuri di dalam tanah lebih banyak dibanding tanaman yang tanpa dilakukan pemangkasan akar serta inokulasi JMA.

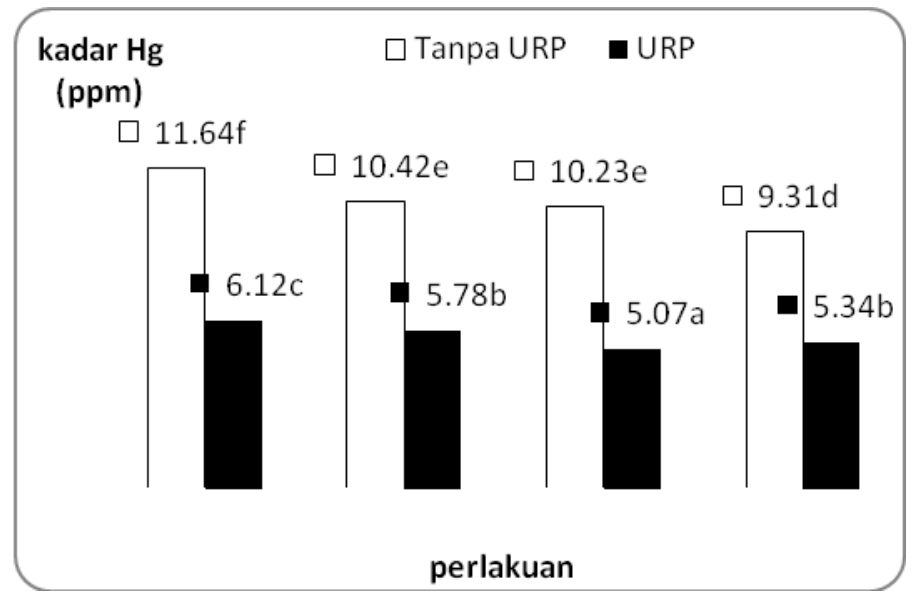

Gambar 1.Rerata kadar Hg (ppm) dalam tanah setelah berlangsung proses fitoremediasi oleh tanaman Akasia selama delapan bulan pada berbagai perlakuan.

Keterangan: huruf kecil yang sama di belakang angka menunjukkan tidak ada beda antara satu dengan yang lain berdasar Uji BNT $\alpha 5 \%$

Kemampuan penyerapan akar terhadap merkuri berpengaruh kepada kadar $\mathrm{Hg}$ dalam tanah. Pada awal proses remediasi, merkuri yang terkandung di dalam tanah rata-rata sebesar 18 ppm. Uji BNT a 5\% menunjukkan bahwa tanah yang mengalami penurunan merkuri terbanyak adalah tanah yang difitoremediasi oleh tanaman Akasia dengan pemangkasan akar disertai inokulasi JMA sebanyak $100 \mathrm{~g} /$ pot.
Di akhir percobaan, $\mathrm{Hg}$ yang terdeteksi di dalam tanah pada perlakuan ini yaitu sebanyak 5,07 ppb, sehingga mengalami penurunan sebesar $71,83 \%$. Sementara itu, kadar merkuri dalam tanah pada kontrol masih relatif banyak, yakni hanya turun $35,33 \%$. Hal ini menunjukkan bahwa tidak ada percepatan pertumbuhan akar lateral maupun perluasan rizosfer oleh hifahifa JMA pada kontrol. 
Kemampuan tanaman Akasia untuk meremediasi merkuri dalam tanah ternyata mendekati kemampuan beberapa jenis tanaman lain mereduksi merkuri di reaktor lahan basah buatan selama tiga hari. Randonuwu (2014) mendapatkan hasil bahwa efisiensi penurunan merkuri dalam reaktor lahan basah Typha sp. sebesar 84.18\%; Eichhornia crassipes sebesar 81,19\%; Nelubium nelumbo sebesar 80,78\%; Ipomoae aquatic sebesar 83,84\%; dan Hydrilla verticillata sebesar $83,96 \%$.

Mengingat tanaman Akasia mampu melakukan remediasi merkuri di dalam tanah dan mengakumulasikannya di dalam akar, maka perlu dirancang teknologi tepat guna untuk mengekstrak merkuri yang terserap jaringan tanaman, agar bisa dimanfaatkan lagi (daur ulang). Langkah ini akan membebaskan jaringan tanaman dari merkuri, sehingga menjadi aman saat dibuang ke lingkungan, serta dapat mencegah pencemaran tanah oleh merkuri kembali.

\section{C.}

\section{ESIMPULAN}

Pemangkasan akar pada tanaman Akasia dan inokulasi Jamur Mikoriza Arbuskula sebanyak 100 $\mathrm{g} /$ pot terbukti bisa menjadi upaya peningkatan fitoremediasi merkuri dalam tanah sisa olahan penambangan emas di daerah Kokap Kabupaten Kulonprogo Daerah
Istimewa Yogyakarta yang berlangsung selama delapan bulan, dengan penurunan sebesar 71,83 $\%$.Hal ini menunjukkan bahwa sistem fitoremediasi dapat digunakan guna mengurangi limbah merkuri, sehingga menjadi salah satu acuan untuk mengurangi pencemaran akibat kegiatan penambangan emas secara tradisional.

D.

\section{AFTAR PUSTAKA}

Anonim. 2001. Peraturan Pemerintah Republik Indonesia Nomor 82 tahun 2001 tentang Pengelolaan kualitas air dan pengendalian pencemaran air, Presiden Republik Indonesia, Jakarta.

Anonim. 2004. Surat Keputusan Menteri Negara Lingkungan Hidup Nonor 202, Baku mutu air limbah bagi usaha dan atau kegiatan pertambangan emas dan atau tembaga, Deputi MENLH Bidang kebijakan dan Kelembagaan Lingkungan Hidup.

Caroline, J. dan Moa, G. A. 2015. Fitoremediasi logam timbal $(\mathrm{Pb})$ menggunakan tanaman melati air (Echinodorus palaefolius) pada limbah industry peleburan tembaga dan kuningan. Seminar Nasional Sains dan Teknologi Terapan III 2015.ISBN 978602-98569-1-0.Institut

Teknologi Adhi Atma Surabaya.

Djam'an, D. F., Enok, R. K., Garry, L. \& Tatiek, K., 2006, Pengaruh pematahan dormansi 
benih pada 2 provenan akasia (Acacia aulacocarpa. A. Cunn. Ex Benth) terhadap viabilitas benih,Buletin Puslitbang Perhutani, Vol IX No 01 Januari 2006, Perusahaan Umum Kehuitanan Negara, Perum Perhutani, Pusat Penelitian dan Pengembangan Perhutani Cepu. ISSN 1411 2175.

Emmyzar, Hermanto. 2004. Rehabilitasi tanah tercemar $\mathrm{Pb}$ menggunakan tanaman akar wangi. Gakuryoku 10:37-40.

Ghosh, M. dan S.P. Singh, 2005, A review on phytoremediationof heavy metal ang utilization of its by product, Applied Ecology and Environmental Research 3 (2): 1-18.

Gomez, K.A dan A.A. Gomez. 1984. Statistical prosedures for agriculture research. John Willey and Sons, Inc. 27 - 100; $214-222$

Kabirun, S. 2004. Peranan mikoriza arbuscula pada pertanian berkelanjutan.Universitas Gadjah Mada Yogyakarta.

Kartika, N. H. 1997. Pengaruh pemotongan akar terhadap pertumbuhan setek panili (Vanilla planifolia Andrews).Fakultas Pertanian Bogor.

Marsono, D. \& Soeseno, O.H., 1992, Prinsip-prinsip silvikultur,
Universitas Gadjah Mada University Press.

Morel, J L, Echevarria,G. dan Goncharova, N. 2006. Phytoremediation of MetalContaminated Soils. Netherland: Springer.

Nur, F. 2013. Fitoremediasi logam berat cadmium (Cd).Biogenesis. Jurnal Ilmiah Biologi. ISSN 2302-1616, Vol 1, No. 1, Juni 2013, hal 74-83.

Nuryani, S. \& Sutanto, R., 2002, Pengaruh sampah kota terhadap hasil dan tahana hara lombok, Jurnal Ilmu Tanah \& Lingkungan, Volume 3 (1). Pp $24-28$.

Pane H, dan Hasanudin A. 2001. Gulma invasive jajagoan (Echinochloacrusgalli L.) dan eceng gondok (Eichornia crassipes (Mart.) Solms )di lahan sawah irigasi. Makalah pada "Seminar Peringatan Hari Keanekaragaman Hayati 2001”.Bogor, 22 Mei 2001.

Purakayastha, T. J dan Chhonkar, P. K. 2010.Phytoremediation of Heavy Metal Contaminated Soils. Berlin Heidelberg: Springer.

Sieverding, E. 1991.Vesicular arbuscular mycorrhiza management in tropical agrosystem.Deutsche

Gesellschaft fur technische Zusammerarbeit (GTZ) G mb $\mathrm{N}$. 